\title{
PARTICULARES ABSTRACTOS: UN CLÁSICO ONTOLÓGICO RECUPERADO
}

\author{
M. Bordes Solanas \\ (Grupo de Epistemologia y Análisis (GEA), UB)
}

Quienes, contra las simplificaciones y abstracciones de los filósofos, suelen decir que "hay más cosas en el cielo y en la tierra de las que sueña vuestra filosotia", con toda seguridad no están pensando en ontologias de particulares abstractos o tropos. Entre otras muchas razones obvias porque una ontología asi - de la que pienso hablar en esta comunicación-segmenta el mundo (la tierra y el cielo) en una miriada de entidades mucho mayor que la que intuitivamente le correspondería. En efecto, la economia en este sentido no se cuenta entre las virtudes de esta propuesta.

Quiero advertir que usaré 'ontología' en un sentido restringido, el que se le da entre filósofos de tradición anglosajona, y que hace referencia al estudio de los tipos básicos de entidades que constituyen el mobiliario del universo. Mi intención en esta exposición breve consistirá simplemente en esbozar las posiciones básicas que han adoptado clásicamente los ontólogos y en proponer una posibilidad históricamente menospreciada que goza hoy de buena fama entre los ontólogos contemporáneos. Por limitaciones de tiempo no podrí argumentarla como se debiera.

Los diferentes tipos de ontologías vienen determinados por dos elementos. Por un lado, el tipo de entidades consideradas metafísicamente primarias. Por otro, los procedimientos de construcción de las entidades derivativas o secundarias respecto de éstas. Teniendo esto en cuenta, examinaré las ontologias clásicas tipificadas. Los mobiliarios más clásicos en la propaganda filosófica han sido frecuentemente los favorecidos por los ontólogos denominados 'realistas', platónicos o aristotélicos. La teoria de la segmentación del mundo en sustancias primeras o concretos y propiedades o universales, de supuesta inspiración aristotélica, atraviesa toda la Edad Media y goza de gran predicamento general en nuestros días. Según esta ontología de sustancia-atributo tan básicos son los objetos concretos (este papel, Bioy Casares) como los universales a partir de los que los caracterizamos (Blancura, Sensibilidad). Ninguno puede ser reducido al otro, ya que sus naturalezas son de diferente cittegoria (Frege disponía de una cierta justificación para esto, a saber, que los concretos son entidades saturadas, mientras que los universales no, ya que no pueden existir sin que un concreto los sature o ejemplilique). Para algunos, no obstante, este mobiliario resulta demasiado barroco y poco funcional, delido especialmente a la poca conlianza empirica que inspiran las misteriosas entidades subsistentes que parecen ser los universales. Por éstas y otras razones surgieron las ontologias nominalistas o particularistas según las que sólo existen concretos en el mundo, es decir, entidades espaciotemporales de más o menos usual referencia deictica. Papeles, personas y otros objetos de designación demostrativa son los objetos metafisicamente primarios; la Blancura y la Sensibilidad se pueden construir como sunas o clases de concretos. Este particularismo, sin embargo, presenta notorias deficiencias a la hora de responder a ciertas graves objeciones de principio en su contra. N. Goodman (1951) y B. Russell (1912) formularon un par de criticas debastadoras contra él, que pueden verse como referentes a su análisis del fenómeno de la predicación, es decir, de su construcción de los universales a partir de los concretos.' Para Russell

1 La objeción planteada por Goodman se le presenta a todo nominalista que quiera construir unjuersales a partir de clases de semejanza de particulares concretos. Es el sigujente. Consideremos los pariculares concretus $\Lambda$, B y C. Supongamos que $A$ es rojo, suave y redondo. B verde, aspero y redondo, y C rojo, áspero y' cuadrado. 
(1912) las ontologias puramente particularistas son meras utopías, ya que, por su argumento toda ontologia ha de aceptar por lo menos un universal, el de semejanza. De ser así, pensaba, una vez aceptado un universal, ¿por qué no aceptarlos todos? No voy a discutir la corrección o no de la consecuencia que extrajo, aunque creo que no es válida (especialmente si en lugar de pensar en las sutiles entidades que son los universales pensamos en si se sigue o no planteada respecto de alimentar a un hijo o a varios). En cualquier caso, B. Russell propuso, hacia 1948, construir los concretos conto haces de universales como una ontología más econónica en categorias que la particularista enfrentada a su objeción. El mobiliario del mundo queda reducido a objetos de una sola categoria, a saber, propiedades, que se combinan mediante la relación de copresencia en haces distintos para determinar unos concretos u otros: Bioy Casares sería la suma de los universales de Sensibilidad, Viveza, Altura,... copresentes en cierto espacio-tiempo, el de su curso vital.

Estas tres propuestas ontológicas, la teoría de sustancia-atributo, la particularista y la universalista, han conformado el muestrario clásico de posibilidades ontológicas. Sin embargo, el muestrario histórico es aún más amplio. Seguidamente presentaré dos posibilidades más que, aunque defendidas en el pasado, sólo se han hecho clásicas hace unas décadas, especialmente gracias a la labor de filósofos como Stout (1923), Williams (1953). y actualmente Campbell (1990) y Bacon (1995). Las dos posibilidades se basan en la tesis de que ni los concretos como Bioy Casares ni los universales como la Sensibilidad son las entidades primarias del universo. Existen entidades mucho más próximas a nosotros psicológicamente que son muy buenos candidatos para construir el mundo (o, al menos, puesto que no tengo pretensiones tan exigentes, se trata de entidades que instrumentalmente nos son muy útiles a la lora de describirlo). La sonrisa de Bioy Casares, el color de este papel o el perimetro de la Moncloa son ejemplos de tales entidades, de bajo grosor cualitativo, que pueden llamarse 'particulares' por su espaciotemporalidad y 'abstractos' por su (aparente) dependencia de los concretos que las poseen. Williams (1953) las llamó 'tropos', favoreciendo una ambigüedad que no viene al caso pero que es fäcilmente prescindible en el contexto de discurso. Estas entidades pueden hacer muy feliz al particularista al permitirle huir de los entia non grata de los universales aun manteniendo, no obstante, una dualidad de categorías entre los concretos y sus atributos. Esta cuarta teoria defiende que el mundo consta de tropos y de concretos, siendo estos últimos el fundamento de los primeros, sin los que no pueden existir. La sonrisa de Bioy Casares depende de la existencia de Bioy Casares, el perimetro de la Moncloa no existiria sin esta codiciada residencia...Esta teoria de tropos puede parecer exótica, pero, desde luego. hay buenas razones para pensar que no es novedosa. Sin forzar a Locke es fácil justificar que, por lo menos en 1689 , creia en alguna contrapartida suya. Por un lado sabemos que Locke profesaba fe de nominalista al alirmar que sólo existe lo particular, que "lo general y lo universal no pertenecen a la existencia real de las cosas, sino que son invenciones y criaturas del entendimiento" (Ensayo sobre el entendimiento hmmano, Ill, iii, I1), que no hay' naturalezas comunes in re. Por otro, defiende la existencia de lo que podemos llamar 'sustancias' (no en el sentido de 'sustrato' sino en el de 'objeto con propiedades'), las entidades primarias de su ontologia. El resultado es que, si las

A, B y C pertenecen a la misma clase da semejanza, pero no forman una "comunidad perfecta" ya que el aspecto en que uno se asemeja a otro no es el mismo para los tres (la relación de semejanza que se da entre ellos no es transitiva). El teórico da tropos eludirá este problema construyendo los universales como clases de semejanza de tropos. Los tropos (simples) no pueden pertenecer a la misma clase de semejanza a no ser que sean absoluta. mente semejantes: no pueden ser semejantes en unos aspectos y no en otros, ya que ellos mismos no son sino aspectos particulares. 
sustancias tienen propiedades como él dice que tienen y si todo lo que existe es particular, las propiedades de las sustancias son particulares abstractos o tropos. El mismo y otros filósofos modernos (Descartes y Hume), los denominaban 'modos'. Es interesante notar que Locke otorga a los modos o troposmucluas de las propiedades de los concretos: según él, existen donde existen los concretos a los que caracterizan y dos modos, como dos concretos, no pueden ocupar el mismo espacio al mismo tiempo.

También Leibniz puede ser considerado en algún sentido tropista. Ya en su "Disputatio metaphysica de principio individui" dice que todo lo constitutivo de los individuos es a su vez individual, y, más tarde, que los accidentes (léase 'tropos') no pueden ser compartidos por más de una sustancia ("no pueden tener, por asi decirlo, un pie en una y otro en otra"). Asi pues, lo que ya Aristóteles (Categorias la20-1b9) describia como entidades que no se dicen de un sujeto pero que están en un sujeto, condenando a los tropos a un papel secundario en ontologia, han sido sobrios sustitutos de los universales en más de una teoria históricamente defendida.

Pues bien, siguiendo con el hilo sistemático del tema, la felicidad del particularista nato al verse libre de los universales con los tropos puede ser sólo felicidad a medias para aquél que además tenga aficiones de corte occamista. Realmente, si disponemos de tropos. ¿por qué seguir defendiendo como prioritarios a los concretos? ¿Por qué no seguir el ejemplo del universalista ahora con Ersätze nominalistamente respetables? Esto es to que la segunda teoria de tropos propone. Bioy Casares es, según ella, un respetable haz de tropos: su sensibilidad, el color de sus ojos, su altura... Técnicamente es el conjunto maximal de sus tropos copresentes. También los universales son reducibles a tropos. La Blancura es el haz de todas las blancuras: la de este papel, la de esta bola de nieve... Técnicamente es una suma maximal de los tropos semejantes entre sí. Universales y concretos son constructos metafisicamente derivativos de tropos. Así pues, el mobiliario del mundo puede disenarse mediante tropos y dos relaciones primitivas: una relación externa, la de copresencia, y una interna, la de semejanza. Con todas las ventajas del particularista, el partidario de esta teoria de tropos puede eludir sus principal desventaja, a saber, la referente a la construcción de los universales, gracias a la transitividad de la relación de semejanza entre tropos, que no está asegurada para concretos (vid. nota 1).

Hasta aquí por lo que respecta a la recuperación de este clásico, como indica el título de esta ponencia. Pero, ¿qué hay de las razones por las que ha sido un clásico olvidado?. ¿por qué la sido una ontologia tan profundamente arrinconada hasta nuestros dias? La razón básica viene dada por la evidente carencia en los lenguajes naturales de términos que designen tropos: sólo compuestos como 'la sonrisa de Bioy Casares' o 'el olor de este perfume' nos sirven para ello, y no sin ambigüedad, con el agravante de que subrayan fuertentente una supuesta secundariedad de los tropos respecto de los concretos, uno de los elementos que conforman el plato fuerte de nuestro vocabulario junto con los términos de predicado.

\section{BIBLIOGRAFIA}

BACON, J. (1989): "A single primitive trope relation", Journal of Philosophical Logic, 18. pp. $141-154$.

-(1995): Universals and property instances: the alphabet of being (Oxford: Blackwell). 
CAMPBELL, K. (1981): "The metaphysics of abstract particulars", Midwest Studies in Philosophy, 6, pp. 477-488.

-11990): Abstract particulars (Oxford: Basil Blackwell). GOODMAN, N. (1951): The structure of appearance (Cambridge: Harvard U. P.).

KÜNG, G. (1964): "Concrete and abstract properties", Notre Dame Journal of Formal Logic, 5

LEWIS, D. (1986): On the plurality of Ilorlds (Oxford: Basil Blackivelt)

RUSSELL (1912): The problents of philosophy (Londres: O. U. P).

SIMONS, P. O. (1994): "Particulars in particular clothing: three trope theories of substance", Philosophy and Phenomenological Research, LIV, 3, pp. 553-574.

WILLIAMS, D. C. (1953): "On the elements of being I", Review of metaphysics, 7 , pp. 3-18.

- On the elements of being II", Review of metaphysics, pp. 172-192. 